\title{
Non-farmers' Preference for Assisting with Farm Tasks as a Method of Health Promotion
}

\author{
Hideo AIZAKI ${ }^{1,2 *}$, Tatsuji ONIMARU ${ }^{3}$, Chie KATAYAMA ${ }^{3}$ and Kenji ISHIDA ${ }^{3}$ \\ ${ }^{1}$ Research Faculty of Agriculture, Hokkaido University \\ (Sapporo, Hokkaido 060-8589, Japan) \\ ${ }^{2}$ School of Agricultural and Resource Economics, The University of Western Australia \\ (Perth, WA 6009, Australia) \\ ${ }^{3}$ Institute for Rural Engineering, National Agriculture and Food Research Organization \\ (Tsukuba, Ibaraki 305-8609, Japan)
}

\begin{abstract}
Increasing attention has been focused on promoting the physical and psychological health of non-farmers through farm activities such as home gardening and allotment gardening. In addition to these two farm activities, another farm activity - assisting with farm tasks - has been recently observed among non-farmers. Assuming that certain activities promote the health of non-farmers, specifically assisting with farm tasks near the home, allotment gardening, home gardening, walking, hiking, light physical exercise, home training with gymnastic equipment, and bowling, the preference for assisting with farm tasks compared to other farm and non-farm activities for health promotion was assessed among nonfarmers in Chiba prefecture, Japan. Based on the best-worst scaling approach, assisting with farm tasks and allotment gardening were found to be the least and second-least preferred activities, respectively, while home gardening was found to be more preferred than these two farm activities. According to our results, decreasing farm task difficulty, reducing the travel cost of visiting a farmer, and asking non-farmers to only assist with tasks that can be conducted at their own pace could increase the nonfarmers' preference for assisting with farm tasks as a method of health promotion.
\end{abstract}

Discipline: Agricultural economics

Additional key words: best-worst scaling, gardening, ordered logit model, relative importance

\section{Introduction}

The key concept for evaluating agriculture is multifunctionality. While the principal role of agriculture is to produce food and non-food products, other roles include flood prevention, biodiversity, landscaping, and cultural heritage (OECD 2001, Aizaki et al. 2006, Renting et al. 2009). Recently, more attention has been focused on promoting the physical and psychological health of nonfarmers through farm activities (Maas et al. 2006, Park et al. 2009, Sommerfeld et al. 2010, van den Berg et al. 2010, Hawkins et al. 2011, Onimaru et al. 2015). In one study, van den Berg et al. (2010) revealed that individuals with allotment gardens have better self-perceived health and well-being scores than their neighbors without an allotment garden. Previous studies regarding non-farmers' farm activity and their health mainly focused on daily farm activities, such as home gardening and/or allotment gardening. Those engaging in home gardening may grow crops, flowers, and other plants in their home garden or in garden planters on the veranda of their home. They could also rent an allotment garden, usually from a farmer, near their home to grow crops, flowers, and other plants.

In addition to these two farm activities, which are also common in Japan, assisting with farm tasks is another farm activity that has been recently observed among non-farmers, especially in urban areas. Assisting with farm tasks is the activity of visiting a farmer near one's home to assist with farm tasks assigned by the farmer. Compared with home gardening and allotment gardening, assisting with farm tasks has a stronger connection with agriculture as conducted by farmers (see Ohe [2009] for details regarding the farm activities of non-farmers in urban areas and the related policies in Japan).

Several previous studies have examined the demand of Japanese non-farmers for daily farm activities. Among

*Corresponding Author: e-mail azk-r@spa.nifty.com

Received 3 June 2015; accepted 14 October 2015. 
these studies, Aizaki (2005) estimated a demand function for allotment gardening in a local area of Japan using discrete choice experiments and a geographical information system, while Yagi (2013) estimated the demand of non-farmers for assisting with farm tasks in Tokyo. In a survey of elderly non-farmers in three major urban areas in Japan, Onimaru et al. (2015) revealed that their willingness and perceived ability affect their intention to assist with farm tasks near their home to promote health. Although valuable, these studies focused on a specific farm activity and did not consider non-farm activities, including the many sport and leisure activities that promote health. A comparison of preferences for farm and non-farm activities should be considered when analyzing the demand for farm activities for promoting health. If this comparison is neglected, the relative importance of each activity cannot be measured and the best means of raising awareness about assisting with farm tasks as a method of promoting health cannot be determined.

To fill this research gap, this study used the best-worst scaling (BWS) approach to examine how non-farmers evaluate the activity of assisting with farm tasks compared to other farm and non-farm activities for promoting health. Although the BWS approach is divided into three types, which include case 1 (object case) BWS, case 2 (profile case) BWS, and case 3 (multiprofile case) BWS (see Flynn [2010] and Flynn \& Marley [2014] for a detailed descriptions of the three types of BWS), this study used case 1 BWS (hereafter, BWS refers to case 1 BWS). The use of BWS, which was developed by Finn \& Louviere (1992) and is applied in various research disciplines, enables the relative importance of items to be estimated, and was therefore suitable for determining preferences for many health-promoting activities. This study also used an ordered logit model to explore the factors affecting non-farmers' evaluation of assisting with farm tasks to promote health.

\section{Data and Methods}

\section{Survey method}

A web survey was conducted in February 2014. A total of 830 respondents were recruited from a survey panel maintained by MACROMILL, a major web survey company in Japan. The respondents were limited to non-farmers living in the Chiba prefecture of Japan, which is contiguous with Tokyo and a well-known agricultural region. To examine the effects of gender and age on the non-farmer's evaluation of the activities, 83 respondents were selected from each of the 10 categories constructed by combining the two main factors of gender (male and female; two categories) and age (20s, 30s, 40s, 50s, and 60s; five categories).

\section{Activities for promoting health}

The following eight activities were assumed to promote the health of non-farmers: assisting with farm tasks near the home (assisting with farm tasks), allotment gardening, home gardening, walking, hiking, light physical exercise (exercise), home training with gymnastic equipment (training), and bowling. The farm activities evaluated were assisting with farm tasks, allotment gardening, and home gardening. Although non-farm activities (i.e., walking, hiking, exercise, training, and bowling) were selected based on responses to the 2011 Survey on Time Use and Leisure Activities (Ministry of Internal Affairs and Communications 2012), the original "walking or light physical exercise" category was divided into the two categories of "walking" and "light physical exercise" for the survey used in this study. This division was deemed necessary because walking is mainly an outdoor activity, while light physical exercise is mainly an indoor activity; therefore, non-farmers' preferences for walking and exercising may differ.

\section{Best-worst scaling}

BWS was used for measuring the relative importance of the eight activities for promoting health. A key feature of BWS is that it enables efficient measurement of the relative importance of a large number of items. If a paired comparison approach is used for measuring the relative importance of eight items, each respondent is required to answer a total of 28 paired comparison questions. If a total of eight items is evaluated, BWS would require each respondent to answer a total of 14 questions. The reason why each respondent would be required to answer 14 questions is that BWS requires a comparison of three or more items in each question and the construction of a combination of items in each question using an experimental design (for applications and detailed information regarding the BWS approach, refer to Flynn [2010], Louviere et al. [2013], Flynn \& Marley [2014], and Aizaki et al. [2014]).

Figure 1 shows a sample of the BWS questions used in this study. Respondents were requested to select the most and least preferred activities for health promotion from a list of four activities. By changing the combination of activities presented to the respondents, the BWS questions were repeated 14 times for each respondent (i.e., 14 BWS questions per respondent). A balanced incomplete block design composed of eight items with 14 rows and four items per row (Cochran $\&$ Cox 1957) was used to create the 14 BWS questions.

Aggregated BWS scores were used for comparing the order of preference for activities among all respondents and/or among subgroups. Although various aggregated BWS scores have been proposed, we used the square root of the ratio of $B_{i}$ to $W_{i}$ (sqrtBW) for activity $i$ :

$$
\operatorname{sqrtB} W_{i}=\sqrt{ } B_{i} / W_{i}
$$

and its standardized version:

standardized (std.) $s q r t B W_{i}$

$$
=100 \times s q r t B W_{i} / \text { maximum } \operatorname{sqrtB} W_{i},
$$


where $B_{i}=\sum_{n} B_{i n}$ and $W_{i}=\sum_{n} W_{i n} ; B_{i n}$ and $W_{i n}$ are the number of times individual $n$ selected activity $i$ as the most and least preferred activity in all presented BWS questions, respectively; std. $s q r t B W_{i}$ is the relative importance of activity $i$ among the eight activities; and the maximum $\operatorname{sqrtB} W_{i}$ is the maximum score among all activities. For example, if the std. sqrtBW for activity $i$ and $j$ is 20 and 40, respectively, activity $j$ is twice (i.e., $40 / 20=2$ ) as important as activity $i$.

The individual level BWS score for assisting with farm tasks was examined to determine which factors affect non-farmers' evaluation of assisting with farm tasks as a method of health promotion. The BWS score of activity $i$ was calculated as follows:

$$
B W_{\text {in }}=B_{\text {in }}-W_{\text {in }} \text {. }
$$

In this study, relative preference was indicated by ordered integer values ranging from -7 to 7 , which referred to the activities selected as the least and most preferred seven times, respectively. An ordered logit model (Greene \& Hensher 2010) was used for the analysis.

Factors that affect non-farmers' evaluation of assisting with farm tasks were assumed to be gender, age, and willingness and ability to assist with farm tasks (Onimaru et al. 2015). To adjust for the possible effects of other individual characteristics on non-farmers' evaluation of assisting with farm tasks, the variables of having experience with farm management, having parents, close relatives, or friends who are farmers, and living near farmland were included and defined as shown in Table 1.

$\mathrm{R}$ ( $\mathrm{R}$ Core Team 2015) along with the package support.BWS (Aizaki 2014, Aizaki et al. 2014) and the function polr() in the package MASS (Venables \& Ripley 2002) was used to prepare the questionnaire and analyze the responses.

\section{Results and Discussion}

Table 2 lists the BWS scores for each activity among all respondents. Only three activities (i.e., walking, exercise, and home gardening) had sqrtBW scores $>1$, meaning that the B score was larger than the $\mathrm{W}$ score for activity $i$. The
sqrtBW scores of the other five activities (i.e., hiking, training, bowling, allotment gardening, and assisting with farm tasks) were $<1$. A remarkable finding was that walking and exercise are relatively strongly preferred, with the std. sqrtBW for the two activities 100 and 77.6, respectively, while that for the other six activities were less than 50 . The order of activities from the most to least preferred for all respondents was (1) walking, (2) exercise, (3) home gardening, (4) hiking, (5) training, (6) bowling, (7) allotment gardening, and (8) assisting with farm tasks. The order of preference for these activities was nearly similar when the respondents were stratified according to male and female subgroups (Table 3 ) and age subgroups (Table 4).

Walking, exercise, and home gardening are activities that are conducted in or around home that impose no or little financial burden. The other five activities require travel from the home to a location where the activity can be conducted and/or impose a financial burden in the form(s) of travel costs, equipment costs, and/or activity fees. These results indicate that the features of activities, such as the need to travel to a different location and the need for a monetary outlay for participation, appear to affect preferences for activities (Franco et al. 2015).

An important finding was that assisting with farm tasks had the lowest sqrtBW score, indicating that it was the least preferred activity. The standardized scores for assisting with farm tasks was 18.9 for all respondents (Table 2), 19.8 and 15.7 for the male and female subgroups, respectively (Table 3), and 21.8, 23.7, 22.0, 13.0, and 14.4 for those in their 20s, 30s, 40s, 50s, and 60s, respectively (Table 4). Allotment gardening also had a low sqrtBW score. Conversely, home gardening was found to be the third-most preferred activity, meaning that it was more preferred than allotment gardening and assisting with farm tasks. The relatively greater preference for home gardening may be not only because it requires no travel and imposes no or few monetary costs, as explained previously, but also because it is easier for non-farmers to conduct than allotment gardening and assisting with farm tasks. Allotment gardening and assisting with farm tasks require various farm skills and

Please select the most and least preferred activities for promoting your health from the following four activities (select one activity for each).

\begin{tabular}{|l|c|c|}
\hline & Most preferred & Least preferred \\
\hline Assisting with farm tasks near the home & $\circ$ & $\circ$ \\
\hline Allotment gardening & $\circ$ & $\circ$ \\
\hline Home gardening & $\circ$ & $\circ$ \\
\hline Walking & $\circ$ & $\circ$ \\
\hline
\end{tabular}

Fig. 1. A sample of best-worst scaling questions in this study 
Table 1. Definitions of independent variables

\begin{tabular}{|c|c|c|}
\hline Variable & Definition & Mean \\
\hline FEMALE & Dummy variable set to 1 if the respondent is female, 0 otherwise & 0.500 \\
\hline AGE30 & Dummy variable set to 1 if the respondent is in their $30 \mathrm{~s}, 0$ otherwise & 0.200 \\
\hline AGE40 & Dummy variable set to 1 if the respondent is in their $40 \mathrm{~s}, 0$ otherwise & 0.200 \\
\hline AGE50 & Dummy variable set to 1 if the respondent is in their $50 \mathrm{~s}, 0$ otherwise & 0.200 \\
\hline AGE60 & Dummy variable set to 1 if the respondent is in their $60 \mathrm{~s}, 0$ otherwise & 0.200 \\
\hline WILLING1 & $\begin{array}{l}\text { Dummy variable set to } 1 \text { if the respondent's answer to the question regarding willingness to } \\
\text { assist with farm tasks is "I agree," } 0 \text { otherwise }\end{array}$ & 0.061 \\
\hline WILLING2 & $\begin{array}{l}\text { Dummy variable set to } 1 \text { if the respondent's answer to the question regarding willingness to } \\
\text { assist with farm tasks is "I rather agree," } 0 \text { otherwise }\end{array}$ & 0.245 \\
\hline WILLING3 & $\begin{array}{l}\text { Dummy variable set to } 1 \text { if the respondent's answer to the question regarding willingness to } \\
\text { assist with farm tasks is "Neutral," } 0 \text { otherwise }\end{array}$ & 0.229 \\
\hline WILLING4 & $\begin{array}{l}\text { Dummy variable set to } 1 \text { if the respondent's answer to the question regarding willingness to } \\
\text { assist with farm tasks is "I rather disagree," } 0 \text { otherwise }\end{array}$ & 0.207 \\
\hline ABILITY1 & $\begin{array}{l}\text { Dummy variable set to } 1 \text { if the respondent's answer to the question regarding ability to assist } \\
\text { with farm tasks is "I agree," } 0 \text { otherwise }\end{array}$ & 0.055 \\
\hline ABILITY2 & $\begin{array}{l}\text { Dummy variable set to } 1 \text { if the respondent's answer to the question regarding ability to assist } \\
\text { with farm tasks is "I rather agree," } 0 \text { otherwise }\end{array}$ & 0.248 \\
\hline ABILITY3 & $\begin{array}{l}\text { Dummy variable set to } 1 \text { if the respondent's answer to the question regarding ability to assist } \\
\text { with farm tasks is "Neutral," } 0 \text { otherwise }\end{array}$ & 0.289 \\
\hline ABILITY4 & $\begin{array}{l}\text { Dummy variable set to } 1 \text { if the respondent's answer to the question regarding ability to assist } \\
\text { with farm tasks is "I rather disagree," } 0 \text { otherwise }\end{array}$ & 0.242 \\
\hline FARMER & Dummy variable set to 1 if the respondent was farmer, 0 otherwise & 0.025 \\
\hline OTHER1 & Dummy variable set to 1 if the respondent's parent(s) is a/are farmer(s), 0 otherwise & 0.070 \\
\hline OTHER2 & Dummy variable set to 1 if the respondent's close relative(s) is a/are farmer(s), 0 otherwise & 0.206 \\
\hline OTHER3 & Dummy variable set to 1 if the respondent's friend(s) is a/are farmer(s), 0 otherwise & 0.095 \\
\hline FARMLAND1 & Dummy variable set to 1 if a farmland is located near the respondent's home, 0 otherwise & 0.371 \\
\hline FARMLAND2 & $\begin{array}{l}\text { Dummy variable set to } 1 \text { if a farmland is located in the respondent's daily life zone during } \\
\text { weekdays, } 0 \text { otherwise }\end{array}$ & 0.149 \\
\hline FARMLAND3 & $\begin{array}{l}\text { Dummy variable set to } 1 \text { if a farmland is located in the respondent's daily life zone during } \\
\text { holidays, } 0 \text { otherwise }\end{array}$ & 0.082 \\
\hline
\end{tabular}

Note: The baseline categories were "20s" for AGE, "I disagree" for WILLING, "I disagree" for ABILITY, "I don't have parents, close relatives, and friends who are farmers" or "I don't know" for OTHER, and "farmland is not located near the respondent's home" or "I don't know" for FARMLAND.

equipment, long work hours, and a high workload. Thus, such tasks may cause anxiety among non-farmers regarding the dangers associated with using farm equipment and/or the physical fatigue associated with conducting farm tasks (Onimaru et al. 2015), which would result in the lower evaluation of assisting with farm tasks and/or allotment gardening.
Other reasons for the relatively greater preference for home gardening may be that it can be enjoyed independently, while assisting with farm tasks and allotment gardening require working collaboratively with others. Relatively more individuals may prefer conducting health-promoting activities at their own pace, which is not possible in allotment gardening or assisting with farm tasks. Furthermore, 
Table 2. Aggregated best-worst scaling scores

\begin{tabular}{lcrcr}
\hline \hline Activity & B & W & sqrtBW & std. sqrtBW \\
\hline Assisting with farm tasks & 645 & 2,514 & 0.507 & $18.9(8)$ \\
Allotment gardening & 713 & 2,389 & 0.546 & $20.4(7)$ \\
Home gardening & 1,561 & 966 & 1.271 & $47.4(3)$ \\
Walking & 2,858 & 398 & 2.680 & $100.0(1)$ \\
Hiking & 1,237 & 1,259 & 0.991 & $37.0(4)$ \\
Exercise & 2,121 & 491 & 2.078 & $77.6(2)$ \\
Training & 1,292 & 1,669 & 0.880 & $32.8(5)$ \\
Bowling & 1,193 & 1,934 & 0.785 & $29.3(6)$ \\
\hline
\end{tabular}

Notes: $n=830$. B and $\mathrm{W}$ are the number of times all respondents selected each activity as the most and least preferred out of the 14 best-worst questions, respectively. sqrtBW and std. sqrtBW are the square root of the ratio of $\mathrm{B}$ to $\mathrm{W}$ for each activity and its standardized version, respectively. Values in parentheses denote the order of activities based on std. sqrtBW.

Table 3. Comparison of aggregated best-worst scaling scores for each activity according to gender

\begin{tabular}{lccccc}
\hline \hline Activity & \multicolumn{2}{c}{ Male $(n=415)$} & & \multicolumn{2}{c}{ Female $(n=415)$} \\
\cline { 2 - 3 } \cline { 5 - 6 } & sqrtBW & std. sqrtBW & & sqrtBW & std. sqrtBW \\
\hline Assisting with farm tasks & 0.519 & $19.8(8)$ & & 0.494 & $15.7(8)$ \\
Allotment gardening & 0.596 & $22.7(7)$ & & 0.499 & $15.9(7)$ \\
Home gardening & 1.105 & $42.1(3)$ & & 1.469 & $46.7(3)$ \\
Walking & 2.625 & $100.0(1)$ & & 2.738 & $87.1(2)$ \\
Hiking & 1.032 & $39.3(4)$ & & 0.950 & $30.2(4)$ \\
Exercise & 1.542 & $58.8(2)$ & & 3.144 & $100.0(1)$ \\
Training & 0.963 & $36.7(5)$ & & 0.794 & $25.3(5)$ \\
Bowling & 0.883 & $33.6(6)$ & & 0.691 & $22.0(6)$ \\
\hline
\end{tabular}

Notes: sqrtBW and std. sqrtBW are the square root of the ratio of best score to worst score for each activity and its standardized version, respectively. Values in parentheses denote the order of activities based on std. sqrtBW.

Table 4. Comparison of aggregated best-worstt scaling scores for each activity according to age categories

\begin{tabular}{|c|c|c|c|c|c|c|c|c|c|c|}
\hline \multirow[t]{2}{*}{ Activity } & \multicolumn{2}{|c|}{$20 \mathrm{~s}(n=166)$} & \multicolumn{2}{|c|}{$30 \mathrm{~s}(n=166)$} & \multicolumn{2}{|c|}{$40 \mathrm{~s}(n=166)$} & \multicolumn{2}{|c|}{$50 \mathrm{~s}(n=166)$} & \multicolumn{2}{|c|}{$60 \mathrm{~s}(n=166)$} \\
\hline & $\begin{array}{l}\text { sqrt- } \\
\text { BW }\end{array}$ & $\begin{array}{c}\text { std. } \\
\text { sqrtBW }\end{array}$ & $\begin{array}{l}\text { sqrt- } \\
\text { BW }\end{array}$ & $\begin{array}{c}\text { std. } \\
\text { sqrtBW }\end{array}$ & $\begin{array}{l}\text { sqrt- } \\
\text { BW }\end{array}$ & $\begin{array}{c}\text { std. } \\
\text { sqrtBW }\end{array}$ & $\begin{array}{l}\text { sqrt- } \\
\text { BW }\end{array}$ & $\begin{array}{c}\text { std. } \\
\text { sqrtBW }\end{array}$ & $\begin{array}{l}\text { sqrt- } \\
\text { BW }\end{array}$ & $\begin{array}{c}\text { std. } \\
\text { sqrtBW }\end{array}$ \\
\hline Assisting with farm tasks & 0.509 & $21.8(8)$ & 0.577 & $23.7(8)$ & 0.528 & $22.0(8)$ & 0.410 & $13.0(8)$ & 0.512 & $14.4(8)$ \\
\hline Allotment gardening & 0.562 & $24.0(7)$ & 0.592 & $24.3(7)$ & 0.562 & $23.4(7)$ & 0.452 & $14.3(7)$ & 0.565 & $15.9(6)$ \\
\hline Home gardening & 1.141 & $48.8(3)$ & 1.109 & $45.5(3)$ & 1.143 & $47.6(3)$ & 1.241 & $39.2(4)$ & 1.818 & $51.1(3)$ \\
\hline Walking & 2.336 & $100.0(1)$ & 2.356 & $96.7(2)$ & 2.400 & $100.0(1)$ & 3.165 & $100.0(1)$ & 3.556 & $100.0(1)$ \\
\hline Hiking & 0.880 & $37.7(6)$ & 0.816 & $33.5(5)$ & 0.991 & $41.3(4)$ & 1.275 & $40.3(3)$ & 1.090 & $30.7(4)$ \\
\hline Exercise & 1.824 & $78.1(2)$ & 2.437 & $100.0(1)$ & 1.995 & $83.2(2)$ & 1.959 & $61.9(2)$ & 2.313 & $65.0(2)$ \\
\hline Training & 0.894 & $38.3(5)$ & 1.028 & $42.2(4)$ & 0.898 & $37.4(6)$ & 0.959 & $30.3(5)$ & 0.647 & $18.2(5)$ \\
\hline Bowling & 1.115 & $47.7(4)$ & 0.685 & $28.1(6)$ & 0.904 & $37.7(5)$ & 0.743 & $23.5(6)$ & 0.537 & $15.1(7)$ \\
\hline
\end{tabular}

Notes: sqrtBW and std. sqrtBW are the square root of the ratio of best score to worst score for each activity and its standardized version, respectively. Values in parentheses denote the order of activities based on std. sqrtBW. 
without considering the health-promoting aspects of these activities, the demand for non-farmers to assist with farm tasks and/or allotment gardening appears to be extremely low. In a local area of Japan, the ratio of individuals who assisted with farm tasks to the total number of residents was forecast at $<1 \%$ (Yagi 2013). In another area, the ratio of allotment gardeners to the total number of residents was estimated at $1.5 \%$ to $7.6 \%$ (Aizaki 2005). Although conducted under specific conditions and with the data being collected in local areas, these forecasts suggest that the low demand may result in a lower evaluation of these activities for health promotion.

Figure 2 shows the distribution of individual BWS scores for assisting with farm tasks - the dependent variable used in the ordered logit model analysis. As expected according to Table 2, a majority of respondents $(589 ; 71.0 \%$ of all respondents) had negative scores for assisting with farm tasks. Moreover, a relatively large number (132; $15.9 \%$ of all respondents) had the lowest score possible (-7) for assisting with farm tasks.

Table 5 shows the estimation results from the ordered logit model analysis. The gender and age dummy variables were not significant at the $10 \%$ level. In contrast, the dummy variables for willingness to assist with farm tasks (i.e., WILLING1 to WILLING4) were significant at the $<1 \%$ level, indicating that willingness to assist with farm tasks affects the likelihood that individuals would change their evaluation of assisting with farm tasks. Two dummy variables for the ability to assist with farm tasks (i.e., ABILITY1 and ABILITY2) were significant at the $10 \%$ and $1 \%$ levels, indicating that the ability to assist with farm tasks marginally affects the likelihood that individu-

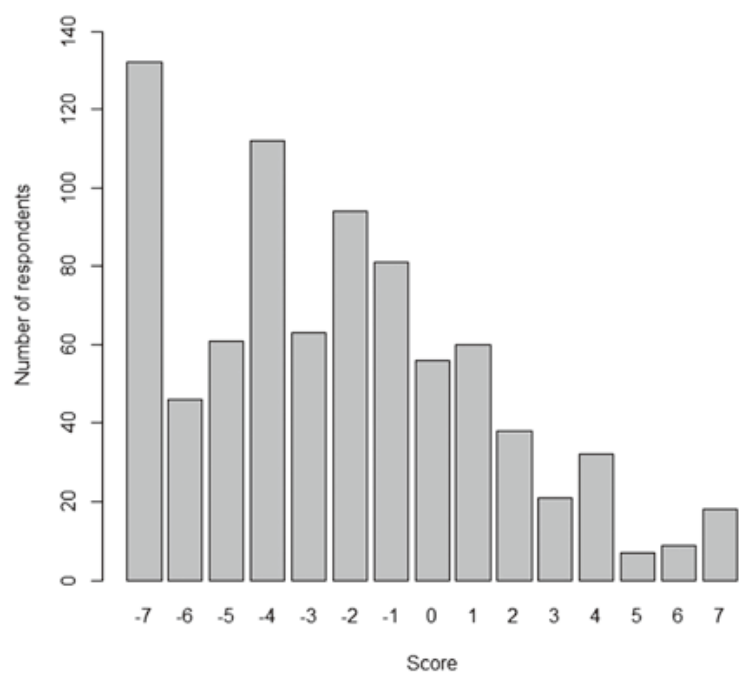

Fig. 2. Distribution of individual level best-worst scaling scores for assisting with farm tasks als would change their evaluation of assisting with farm tasks. Dummy variables of having experience with farm management, having parents, close relatives, or friends who are farmers, and living near farmland (i.e., FARMER to FARMLAND3) were not significant at the $10 \%$ level. As in the results of Onimaru et al. (2015), these estimation results suggest that the willingness and ability of non-farmers to assist with farm tasks affect their intention to assist with

Table 5. Results from the ordered logit model analysis

\begin{tabular}{|c|c|c|}
\hline Variable & Coefficient & $\mathrm{t}$-value \\
\hline FEMALE & 0.075 & 0.605 \\
\hline AGE30 & 0.290 & 1.473 \\
\hline AGE40 & 0.072 & 0.369 \\
\hline AGE50 & -0.127 & -0.646 \\
\hline AGE60 & 0.130 & 0.655 \\
\hline WILLING1 & 3.790 & 11.661 \\
\hline WILLING2 & 2.866 & 12.497 \\
\hline WILLING3 & 1.341 & 6.269 \\
\hline WILLING4 & 0.674 & 3.243 \\
\hline ABILITY1 & 0.563 & 1.720 \\
\hline ABILITY2 & 0.568 & 2.386 \\
\hline ABILITY3 & -0.004 & -0.017 \\
\hline ABILITY4 & -0.051 & -0.230 \\
\hline FARMER & 0.378 & 0.927 \\
\hline OTHER1 & -0.072 & -0.285 \\
\hline OTHER2 & 0.138 & 0.874 \\
\hline OTHER3 & 0.200 & 0.975 \\
\hline FARMLAND1 & -0.154 & -1.052 \\
\hline FARMLAND2 & -0.018 & -0.096 \\
\hline FARMLAND3 & 0.383 & 1.569 \\
\hline$\mu 1$ & -0.548 & -2.450 \\
\hline$\mu 2$ & -0.127 & -0.577 \\
\hline$\mu 3$ & 0.344 & 1.569 \\
\hline$\mu 4$ & 1.119 & 5.007 \\
\hline$\mu 5$ & 1.548 & 6.806 \\
\hline$\mu 6$ & 2.222 & 9.448 \\
\hline$\mu 7$ & 2.869 & 11.789 \\
\hline$\mu 8$ & 3.374 & 13.495 \\
\hline$\mu 9$ & 4.029 & 15.469 \\
\hline$\mu 10$ & 4.553 & 16.810 \\
\hline$\mu 11$ & 4.913 & 17.549 \\
\hline$\mu 12$ & 5.701 & 18.485 \\
\hline$\mu 13$ & 5.959 & 18.544 \\
\hline$\mu 14$ & 6.403 & 18.298 \\
\hline
\end{tabular}

Note: $\mu 1-14$ indicate threshold parameters. 
farm tasks, and that ability has a lower impact on intention than willingness.

\section{Conclusion}

This study evaluated the preference for assisting with farm tasks, allotment gardening, home gardening, and five non-farm activities for promoting the health of non-farmers. The results revealed that assisting with farm tasks and allotment gardening were the least and second least preferred activities, while home gardening was more preferred than these two farm activities. According to our findings, difficulties in assisting with farm tasks, the travel cost of visiting a farmer, and the need to work collaboratively with others may be responsible for the low preference for assisting with farm tasks. Therefore, we concluded that the following activities could increase the preference for assisting with farm tasks among non-farmers:

(1) Fractionalize farm tasks according to the skills required to conduct the tasks, and then request non-farmers to assist with only unskilled tasks that are easy for them to do.

(2) Develop agricultural machinery and/or equipment that reduce the difficulty of skilled tasks, which could subsequently increase the number of (unskilled) tasks for non-farmers.

(3) Provide a free chauffeur service for non-farmers to reduce the travel cost of visiting a farmer in cooperation with local community organizations that are interested in farm activities. Such cooperation would also reduce the farmers' cost of recruiting (e.g., advertising) nonfarmers to assist with farm tasks.

(4) Ask non-farmers to only assist with tasks that can be conducted at their own pace to avoid the need to work collaboratively with others.

This study faced two limitations that may have affected the results. First, the population was limited to non-farmers in one prefecture of Japan. A survey targeting a larger population (i.e., the entire population of Japan) is necessary to formulate a general conclusion. Second, the survey collected limited, specific information regarding home gardening, allotment gardening, and assisting with farm tasks. Within- or between-subject experiments should be conducted to examine more ways of raising awareness about assisting with farm tasks as a method of health promotion. While this study assumed that the farmers providing the farm tasks lived near the respondents in urban areas, farmers living in rural areas further away from non-farmers could also provide the tasks. Non-farmers could enjoy this farming/agricultural leisure activity on a non-daily basis, which might change how they evaluate assisting with farm tasks as a method of health promotion.

\section{Acknowledgements}

This work was supported by the science and technology research promotion program for agriculture, forestry, fisheries and food industry.

\section{References}

Aizaki, H. (2005) Nougyou nouson no keikaku hyouka (Economic valuation of agricultural and rural development projects). Association of Agriculture \& Forestry Statistics, Tokyo, Japan, 219-243 [In Japanese].

Aizaki, H. (2014) support.BWS: Basic functions for supporting an implementation of best-worst scaling, $R$ package version 0.1-1. URL http://CRAN.R-project.org/package=support. BWS.

Aizaki, H. et al. (2006) Contingent valuation approach in measuring the multifunctionality of agriculture and rural areas in Japan. Paddy and Water Environment, 4, 217-222.

Aizaki, H. et al. (2014) Stated preference methods using R. CRC Press, Boca Raton, FL.

Cochran, W. G. \& Cox, G. M. (1957) Experimental designs. Second edition. John Wiley \& Sons, Inc., Hoboken, NJ.

Finn, A. \& Louviere, J. J. (1992) Determining the appropriate response to evidence of public concern: The case of food safety. Journal of Public Policy \& Marketing, 11(1), 12-25.

Flynn, T. N. (2010) Valuing citizen and patient preferences in health: Recent developments in three types of best-worst scaling. Expert Review of Pharmacoeconomics \& Outcomes Research, 10(3), 259-267.

Flynn, T. N. \& Marley, A. A. J. (2014) Best-worst scaling: Theory and methods. In Handbook of Choice Modelling, eds. Hess, S. \& Daly, A., Edward Elgar, Cheltenham UK, 178-201.

Franco, M. R. et al. (2015) Eliciting older people's preferences for exercise programs: A best-worst scaling choice experiment. Journal of Physiotherapy, 61, 34-41.

Greene, W. H. \& Hensher, D. A. (2010) Modeling ordered choices: A primer. Cambridge University Press, Cambridge, UK.

Hawkins, J. L. et al. (2011) Allotment gardening and other leisure activities for stress reduction and healthy aging. HortTechnology, 21(5), 577-585.

Louviere, J. J. et al. (2013) An introduction to the application of (case 1) best-worst scaling in marketing research. International Journal of Research in Marketing, 30, 292-303.

Maas, J. et al. (2006) Green space, urbanity, and health: how strong is the relation? Journal of Epidemiology and Community Health, 60, 587-592.

Ministry of Internal Affairs and Communications (2012) The 2011 survey on time use and leisure activities. URL http:// www.stat.go.jp/english/data/shakai/index.htm.

OECD (2001) Multifunctionality: Towards an analytical frame- 
work. OECD, Paris, France.

Ohe, Y. (2009) Toward consumer-participatory utilization of urban farmland: Case of allotment gardens. Syoku to midori no kagaku (HortResearch), 63, 9-17 [In Japanese with English summary].

Onimaru, T. et al. (2015) Analyzing the structure of elderly nonfarmers' participation in farming activities in urban areas: Focus on health promotion. Nouson kougaku kenkyuusyo gihou (Technical Report of the National Institute for Rural Engineering), 217, 63-74 [In Japanese with English summary].

Park, S. et al. (2009) Physical and psychological health conditions of older adults classified as gardeners or nongardeners. HortScience, 44(1), 206-219.

R Core Team (2015) R: A language and environment for statistical computing. R Foundation for Statistical Computing, Vienna, Austria. URL http://www.R-project.org/.
Renting, H. et al. (2009) Exploring multifunctional agriculture: A review of conceptual approaches and prospects for an integrative transitional framework. Journal of Environmental Management, 90, S112-S123.

Sommerfeld, A. J. et al. (2010) Growing minds: Evaluating the effect of gardening on quality of life and physical active level of older adults. HortTechnology, 20(4), 705-710.

van den Berg, A. E. et al. (2010) Allotment gardening and health: A comparative survey among allotment gardeners and their neighbors without an allotment. Environmental Health, 9:74.

Venables, W. N. \& Ripley, B. D. (2002) Modern applied statistics with $S$. Fourth edition. Springer, New York.

Yagi, H. (2013) Site location and demand for the farm experience business in urban areas: An empirical analysis in Tokyo Metropolis prefecture. Nouson keikaku gakkaishi (Journal of Rural Planning), 32, 323-328 [In Japanese with English summary]. 